\title{
Quality Effects of Investment Projects and Their Effect on Current House Prices: Application of Hedonic Pricing Approach
}

\author{
Lamessa Addisu Gosa \\ Assosa University, College of Business and Economics; Lecturer; Department of Economics \\ Gemachis Debala Biru \\ Assosa University, College of Business and Economics; Lecturer; Department of Accounting and Finance
}

\begin{abstract}
By virtue of their nature, all sorts of investment projects pose environmental disamenities like disfiguration of the natural scene, congestion, noise and pollution of different types. The study is framed to examine environmental impacts of investment projects (Hansom Glass Factory) and their effects on houses transaction values in Adama town (Picock area). Estimation of such negative impacts on current house values, which is reflected as a proxy estimation of distance from the project, was measured using a Hedonic Pricing Approach. Data on current values of residential houses in Adama town (Picock) were taken considering residences residing up to 2300 meters away from the factory for the year 2015. Data were generated for 170 houses at random that reside to the West and South-West directions of Hansom Glass Factory. A Hedonic Price Function was employed for analyzing the data using STATA(11). The study came up with that many of the hypothesized variables significantly affected house transaction prices at different levels of probability $(\mathrm{P}<0.001$ and $\mathrm{P}<0.05)$. The result revealed that residential houses that reside bordering the factory were valued less significantly than their equivalents built away from the factory. Positioning investment projects (industrial parks) explicitly at periphery of towns can avoid coincidence of investment externalities with societal, environmental and economic welfare. To minimize externalities investment projects, emerging cities and towns should develop inclusive master plans forecasts that explicitly identifies future land use for future development agendas. In addition, there should be multidimensional environmental and social impact assessment carried out be external experts before implementation of such projects.
\end{abstract}

Keywords: Hedonic pricing, Industrial parks, House values, Externality

DOI: $10.7176 / \mathrm{JESD} / 12-9-03$

Publication date:May $31^{\text {st }} 2021$

\section{INTRODUCTION}

\subsection{Background}

In the move from agriculture-led to industry-led economy, expansion of investment projects (factories and industries) is a crucial agenda of countries. Today, there are many factories being built in Ethiopia and the number of these factories is increasing sharply beginning from 2000 and taking a share of about $21.31 \%$ of the country's GDP. The majority of these factories (small and large scale) are mainly confined to Addis Ababa.

Almost all sorts of investment activities affect the environment directly or indirectly. The establishment of industries/factories however, need to be in a manner that they can have minimized externalities. Factories should be established on the basis of legal entities that favor environmental social welfare in the vicinity of the project. There should be responsibility for this and any body of a country representation should ensure that each investment project must be subjected to an initial environmental review (FAO, 2012).

This in turn calls for serious attention to the environment with a certain regulations. Failure to position industrial parks (sole factories) in a specified region which are isolated from residential villages, avoiding/minimizing externalities environmental amenities will be a difficult task.

There are different techniques of environmental resource valuation. Of these, revealed preference, more specifically, the hedonic approach is the most commonly used one. Hedonic pricing methods are useful in identifying the impact of the various externalities of projects. Rosen (1974) defined hedonic prices can be explained as implicit prices of attributes that are revealed to economic agents from observed prices of differentiated products and the specific amounts of characteristics associated with them. In a hedonic price analysis, housing prices are regressed on a vector of inherent attributes. Thus, a hedonic equation helps to explain housing prices in terms of the house's own characteristics like the type of dwelling, age, floor area, neighborhood characteristics and accessibility to work places (Kaufman and Cloutier, 2006).

A hedonic pricing approach identifies the values of marketed goods based on the premise that the property's sale price is determined by both the internal factors of the property itself and the external characteristics (externalities) that influence the property (Monson 2009).

Ridker and Hening (1967) presented the first empirical evidence that air pollution affects property values. They argued that the coefficient on air pollution variable in the regression equation could be used to predict the 
change in the price of any residence conditioned on a change in its air pollution level. Afterwards, hedonic price approach has been used for estimating the effect of air quality on residential house prices.

\subsection{Problem Justification}

In Ethiopia, most of the factories are established in sites closely bordering residential villages. This has multitude of externalities to residents like pollution (solid and liquid wastes, smoke, etc.), noise, congestion and disfiguration (obstruction) of the natural scene of the place.

During establishment of investment projects, priority emphasis was given to the expected return and forecast of future negative externalities on environmental and social welfare was given little emphasis. In addition, studies that focused on the negative impact of these factories in Ethiopia is nearly nil. In Ethiopia, no works that evaluate such factories using hedonic pricing approach are available. This study examined the negative impacts of a factory on residential house values. The study also can help policy makers have insight of industrial amenities posed on residents and their effects on social and economic welfare. The impact of such investment projects may not always be in direct and visible way but can be perceived as they significantly affect resource values due to their existence, wastes they release or disfigured scenic value of the area.

Addressing the issue investment externalities will help development planners and policy makers make inclusive forecasts while drafting master plans for cities and towns thereby enabling conditions for best land use plans (industrial parks from residential villages).

\subsection{Objectives of the Study}

The overall objective of this study was to examine the environmental impact of Hansom Glass Factory and the in turn consequence on residential house values.

This study was designed for achieving the following specific objectives.

1. To estimate the impact of negative externalities of Hansom Glass Factory on residential house values

2. To examine the environmental and societal welfare consequences of Hansom Glass Factory in its vicinity

\section{DESCRIPTION OF DATA AND RESEARCH APPROACH}

In order to apply a hedonic pricing approach for quantifying the impact of factories on house transaction values, Hansom Glass Factory (located at Picock area in Adama city) was a subject to this study for in the year 2015. Then through individual interviews (data including house structures, proximity to project sites, project characteristics and neighborhood characteristics).

Hansom Glass Factory was jointly established by CGC Overseas Construction Group Ltd and China-Africa Development Fund. It is built on $114,607 \mathrm{~m}^{2}$ area produces about 42,000 tons of glass a year. It also recycles used and broken glasses (Ethiopian Review Report, 2009).

Major industries of the country are concentrated in Addis Ababa and Hansom Glass Factory was taken as a representative one for this study. In order to take data regarding proximity of residential houses to this factory, a distance of 2300 meters was set as a boundary beyond which the negative externality of the factory on house values is assumed to be negligible.

Our hypothesis is that residential house prices are a function of distance of the house to the factory, neighborhood, factory and structural characteristics of the house. The effect of distance of houses to the factory was taken by taking intervals every 250 meters. The assumption is house values increase as their distance from the factory increases.

Neighborhood characteristics include proximity of the house to highway and work place, crowdedness of the village, scenery and topographic conditions. Similarly, house prices are assumed to be determined by their structural characteristics like floor area, number of rooms, presence of parking and gardens and level internal furniture. Factory characteristics like intensity of pollution was another variable that can affect house prices.

\subsection{Econometric Model Specification}

The econometric model is specified as follows:

$P_{i}=f\left(D_{1}, \ldots, D_{N}+N_{1}, \ldots, N_{o}+F_{1}, \ldots, F_{p}+S_{1}, \ldots, S_{Q}\right)+\varepsilon_{i}$

$\mathrm{P}_{\mathrm{i}}=$ Houses transaction price

$\mathrm{f}=$ The function relating the house price with distance of the house to the factory (D), neighborhood characteristics of the house $(\mathrm{N})$ and structural characteristics of the house $(\mathrm{S})$.

As Rosen (1974), the following utility function can be developed for a person living in a house: 
$U_{i}=U\left(x: D_{1}, \cdots D_{N}+N_{1}+N_{o}+C+S_{1}, \ldots, S_{Q}\right)+\varepsilon$

This utility equation is assumed to be strictly concave and $\mathrm{x}$ is the price of all other goods consumed.

$Y_{i}=P_{i}\left(x: D_{1}, \ldots D_{N}+N_{1}+N_{o}+F_{1}, \ldots, F_{P}+S_{1}, \ldots, S_{Q}\right)+x$

Then, by choosing $\mathrm{x}$ and the budget constraint

$$
\left(D_{1}, \ldots, D_{N}+N_{1}, \ldots, N_{O}+F_{1}, \ldots, F_{P}+S_{1}, \ldots, S_{Q}\right)
$$

individual utility can be maximized for satisfying the budget.

Natural $\log$ specification is a widely employed method for model estimation as it allows for a simple interpretation of estimated coefficients as elasticity (Freeman, 1993).

Then, it is possible to model price of a house $\mathrm{i}$ as shown below:

$$
\ln P_{i}=\alpha+\sum_{N=1} \beta_{N} D_{i, N}+\sum_{O=1} \gamma_{l} N_{i, O}+\sum_{P=1} \delta_{P} F_{i, P}+\sum_{Q=1} \eta_{Q} S_{i, Q}+\varepsilon_{i}
$$

Where

$\alpha$ is constant

$\beta, \gamma, \delta$ and $\eta$ are coefficients to be estimated and

Variables of distance, neighborhood, factory and structural characteristics are indexed by letters N, O, P and Q.

The coefficients of Equation (4) were estimated using Ordinary Least Squares (OLS). In order to check the existence of heteroskedasticity, the White's test of consistent covariance matrix was used. In addition, log transformation (ln) of some variables (house prices, distance to factory and distance to highway) were used to minimize the chances of heteroskedasticity that can arise as a result inflated figures.

\subsection{Major Assumptions}

By its very nature, hedonic pricing approach requires large amount of data for analysis. However, due to the absence of documented house transaction price in Ethiopia, a limited amount of houses whose values were estimated based on the common judgments made by house owners, city planning experts and house brokers.

\section{EMPRICAL RESULTS}

\subsection{The Situation}

Currently, there are different investment projects that are under operation at varying scales in Addis Ababa. Hansom Glass Factory is one of the relatively big factories that was jointly established in 209 by share holders of CGC Overseas Construction Group Ltd and China-Africa Development Fund on an area of $114,607 \mathrm{~m}^{2}$.

The factory is situated bordering the main Addis Ababa-Adama highway. More specifically, the factory is bordered by the highway to the East, lateral road to the South (which is in turn borders the communal residential apartments) and residential villages to the North and West.

\subsubsection{Residents' voice}

Respondent groups including house owners, traders, house brokers and shoe makers were interviewed regarding the major challenges posed by the factory. All confirmed that the factory has serious smoke hazard during its operation. They complain that the smoke released by the factory causes coughing and sneezing to people living in the immediate surroundings of the factory. According to an anonymous shoe maker respondent, the smoke released by the factory is so dense and forms a dense cloud (usually during calm days) to the extent that blocks the sun. In such conditions, respondents confirmed that they suffer from coughing and sneezing. In astudy dealing the impact of glass factory in Egypt, Abdel-Rasoul, et al. (2013) reported that tuberculosis arising from silcon dioxide ( silica) and other hazards are common to humans.

\subsubsection{Industrial site and the Ethiopian context}

In order to avoid hazards to people, industrial sites are usually placed at periphery of cities and towns. This is practiced in many developed countries. But, this doesn't hold in Ethiopia. Even thought positioning factories and industries is allowed at periphery areas, these sites are becoming center areas as most towns in Ethiopia are expanding spectacularly. Factories located outside towns are now becoming centers. This is particularly true for Addis Ababa area.

\subsubsection{Externalities}

Air pollution

The most apparent impact of the project is smoke release during operation. On calm (non-windy) days, the smoke over the factory chimney forms heavy cloud the sometimes blocks the sun. Feedback from respondents revealed that smoke scattering to villages causes coughing, sneezing and tearing on humans. A study made on Egyptian workers in glass industry indicated noise, exposures to respirable airborne particulates especially silica 
$\left(\mathrm{SiO}_{2}\right)$ that leads to chronic effects such as decreased pulmonary function, lung disease, complicated pneumoconiosis (silicosis, the most important and oldest occupational lung diseases worldwide specially in developing countries) and silico-tuberculosis, ergonomic hazards, physical hazards, radiant energy, heat stress disorders and infrared radiation (Abdel-Rasoul, et al., 2013).

\section{Disamenitiey}

The factory lies to the East of the residential houses under consideration along the Addis Ababa-Jimma highway and prevents the ease of access to the main road.

\subsection{Results of the Hedonic Price Function}

Results that are consistent with previous model results were obtained for the hedonic pricing function. And as the earlier hypothesis, different variables were found to significantly influence residential house transaction prices. The marginal implicit price, which is the effect a small change in an independent variable has on house transaction price given that all other factors remain constant, were estimated for the different characteristics under consideration.

\section{Distance of a house to the factory (LnDistance)}

The log transformation of distance of a residential house to the factory was found to be consistent with the earlier perdition. It significantly $(\mathrm{P}<0.001)$ and positively influenced price of residential houses. Houses residing nearer to the factory were found to be influenced by the various impacts of the factory and are valued less as compared to houses located further away. An increase in distance between a residential house to the factory increases by $1 \mathrm{~m}$, price of a residential house increases by $21.46 \%$, ceteris paribus (Table 1). Vor and Groot (2009) reported distance of a residential house to the nearest factory as a determinant variable in a hedonic approach for examining the impact of industrial sites on residential house values.

Table 1. Estimation of the Hedonic Price Function

\begin{tabular}{lcccc}
\hline LnPrice & Coefficient & Standard Error & t-Value & $\mathrm{P}>/ \mathrm{t} /$ \\
\hline LnDistance & 0.2145953 & 0.0273474 & 7.85 & 0.000 \\
LnDist_highway & -0.3091639 & 0.0691967 & -4.47 & 0.000 \\
Crowdedness & -0.0323213 & 0.0148322 & -2.18 & 0.031 \\
Access to work & 0.060305 & 0.0162651 & 3.71 & 0.000 \\
Noisy business & -0.0145081 & 0.0258445 & -0.56 & 0.575 \\
Pollution intensity & -0.0599905 & 0.0155552 & -3.86 & 0.000 \\
Floor area & 0.0011428 & 0.0017199 & 0.66 & 0.507 \\
Parking & -0.0214842 & 0.023013 & -0.93 & 0.352 \\
Scenery & -0.0055516 & 0.0146272 & -0.38 & 0.705 \\
Topography & -0.0012855 & 0.0129043 & -0.01 & 0.921 \\
Garden & -0.0218443 & 0.0239861 & -0.91 & 0.364 \\
Furnished & 0.0383212 & 0.0303064 & 1.26 & 0.208 \\
Rooms & -9.0137854 & 0.0113837 & -1.21 & 0.228 \\
Constant & 11.95773 & 0.4045459 & 29.56 & 0.000 \\
\hline
\end{tabular}

Number of obs $=170 ;$ Prob $>F=0.0000 ;$ R-Squared $=0.7554$; Adj R-Squared $=0.7350$

\section{Crowdedness}

Crowdedness $^{1}$ of a village (neighboring houses) is another important variable determining prices of residential houses. This variable significantly $(\mathrm{P}<0.05)$ and negatively affected house prices. Houses that are in a crowded village were found to be cheaper than those in a calm village. This is because people usually fear theft, robbery, and other crimes when there are unknown people living in a village. In a similar study, V or and Groot (2009) found that crime reports in a village are important factors affecting residential house values.

As one would expect, most studies show that the number of rooms and bedrooms (Fletcher, et al., 2000; Li and Brown, 1980 and Adair et al., 2000), the number of bathrooms (Garrod and Willis, 1992; Linneman 1980) and, generally speaking, the size of the residence (Carroll, Clauretie and Jensen, 1996; Rodriguez and Sirmans, 1994) affect positively the price of houses (Pashardes and Savva, 2009).

\section{Access to work}

Proximity of a house to work place is another important factor positively determining house prices. The finding is in confirmation with our hypothesis and as seen in Table 1, access to work place positively and significantly $(\mathrm{P}<0.01)$ affected prices of houses. From this result one understands that when a house is closer to a work place by $1 \mathrm{~m}$, its value increases by $6 \%$. This is because people prefer residential sites and houses that are in the most convenient vicinity of working areas as this minimizes transportation cost, saves to-and-fro travel time and help them control their home at a short distance.

\footnotetext{
${ }^{1}$ Villages with high population density, high noise, disturbances, and usually, people living in jointly rented houses and involved in informal economic sectors.
} 


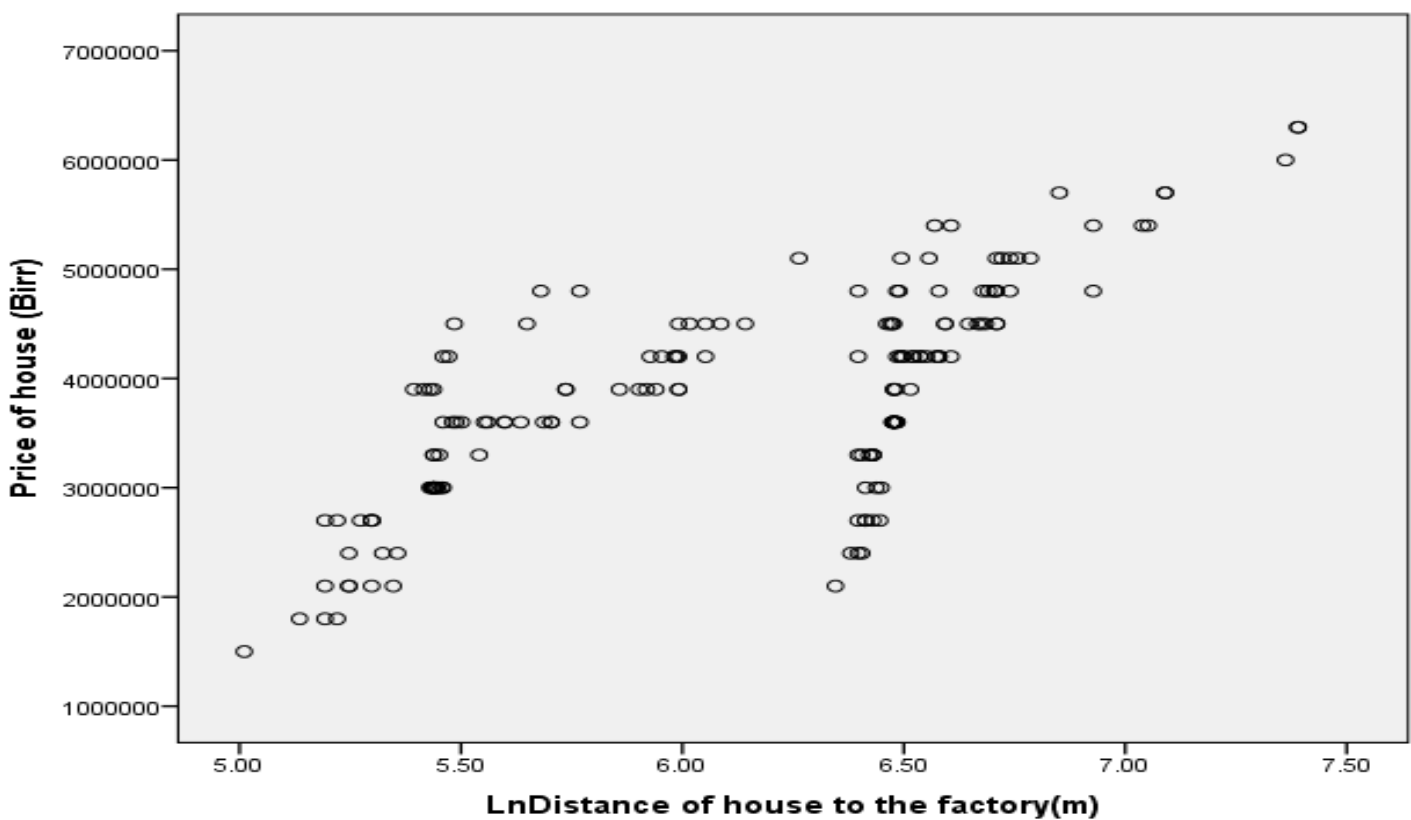

Figure 1. House values plotted as function of distance from the factory

The graph indicates that externalities of factory are site specific and relatively significant up to some distances. This resulted in an inverse relationship between distance and house transaction prices.

\section{CONCLUSION AND POLICY DISCUSSIONS}

\subsection{Conclusion}

The central theme of this paper was to estimate the impact of Honsom Glass Factory on current residential house transaction values in Adama town (Picock area) using a hedonic pricing model during the year 2017. Results that were consistent with other previous works were obtained and the model showed overall significance of $\mathrm{P}<0.0000$ with adjusted R-Squared value of 0.7350 . This indicates that the model was well-fitted explaining about $74 \%$ of the variability in house transaction price was explained. The impacts of the factory were proxied by estimating distance change on residential house transaction prices. The result indicated that house values were found to significantly vary with predicted factors.

The study characterized a wider set of variables and identified those that have substantially determined residential house prices. It was found that house transaction prices significantly

\subsection{Recommendations}

In order to ensure societal welfare and healthy community, city administration and urban policy makers should give emphasis on positioning industrial parks with clear demarcation from residential villages and public institutions like schools.

To minimize externalities investment projects, emerging cities and towns should develop inclusive master plans forecasts that explicitly identifies future land use for future development agendas. In addition, there should be multidimensional environmental and social impact assessment carried out be external experts before implementation of such projects.

Adoption and implementation of smoke absorbing factories in permitting conditions can minimize externalities (mainly pollution) to the nearby dwellers.

Through time, the cumulative effect of externalities (mainly smoke) can undoubtedly bring about public discourses and thus holding public consultation before establishment of such investment projects should be given emphasis.

A wider scope research employing a hedonic pricing approach with more extensive data and alternative estimation techniques can give better conclusive results.

\section{REFERENCES}

Abdel-Rasoul GM, Al-Batanony MA, Abu-Salem ME, Taha AA, Unis F (2013) Some Health Disorders among Workers in a Glass Factory. Occup Med Health Aff 1: d06.doi: 10.4172/2329-6879.1000106.

Adair, A., McGreal, S., Smyth, A., Cooper, J. and Ryley, T. (2000) 'House price and accessibility: The testing of relationships within the Belfast urban area', Housing Studies, 15 (5): 699-716.

CAPMS (Central Agency for Public Mobilization and Statistics) (2006). Egypt. 
Carroll, T. M., Clauretie, T. M., et al. (1996) 'Living next to godliness: Residential property values and churches', Journal of Real Estate Finance and Economics, 12: 319-330.

FAO (Food and Agriculture Organization of the United Nations), (2012). Environmental Impact Assessment Guidelines for FAO's Field Projects, Rome.

FDRE (Federal Democratic Republic of Ethiopia), (2000). Environmental Protection Authority Environmental Impact Assessment Guideline, Addis Ababa.

Fletcher, M., Gallimore, P. and Mangan, J. (2000) 'Heteroskedasticity in hedonic house price models', Journal of Property Research, 17 (2): 93-108.

Freeman, A.M., 1993. The Measurement of Environmental and Resource Values: Theory and Methods, 2nd edition. Washington DC: RFF Press.

Garrod, G. and Willis, K. (1992) 'Valuing the goods characteristics - an application of the hedonic price method to environmental attributes', Journal of Environmental Management, 34 (1): 59-76. Journal of Political Economy 82, 34-55.

Kaufman, D.A. and N.R. Cloutier, 2006. The Impact of Small Brownfields and Greenspaces on Residential Property Values. Journal of Real Estate Finance and Economics 33, 19-30.

Li, M. and Brown, H. J. (1980) 'Micro-neighbourhood externalities and hedonic housing prices', Land Economics, 56 (2): 125-141.

Linneman, P., 1980. Some empirical results on the nature of the hedonic price function for the urban housing market, Journal of Urban Economics, 8 (1): 47-68.

Monson, M., 2009. "Valuation Using Hedonic Pricing Models." Cornell Real Estate Review 7:62-73.

Pashardes S. and C.S. Savvab, 2009. Factors Affecting House Prices in Cyprus: 1988-2008. Cyprus Economic Policy Review, Vol. 3, No. 1, pp. 3-25 (2009) 1450-4561. Residential Property Values. Journal of Real Estate Finance and Economics 33, 19-30

Ridker, Ronald G., and John A Henning (1967) “ The Determinants of Residential Property Values with Special Reference to Air Pollution". The Review of Economics and Statistics 49:2, 246-57. 